\title{
First report of tomato spotted wilt virus infecting parlor palm (Chamaedorea elegans) with leaf mosaic and ring spot disease in Korea
}

\author{
Hyo-Jeong Lee ${ }^{1} \cdot$ Na-Kyeong Kim ${ }^{1} \cdot$ Su-Yeon Hwang ${ }^{1} \cdot$ Kwang-Yeol Yang $^{1} \cdot$ Rae-Dong Jeong $^{1}$ (ID
}

Received: 13 June 2021 / Accepted: 15 October 2021 / Published online: 26 October 2021

(c) Società Italiana di Patologia Vegetale (S.I.Pa.V.) 2021

Keywords Chamaedorea elegans $\cdot$ Korea $\cdot$ Tomato spotted wilt virus

The parlor palm (Chamaedorea elegans) is one of the most desirable houseplant palms in temperate regions and grows mainly in gardens in Southeastern USA (Henderson et al. 1997). There have been no previous reports of viruses infecting C. elegans. In March 2021, virus-like symptoms, including mild mosaic and formation of mild chlorotic ring spots, were observed on C. elegans leaves in a commercial greenhouse in Gwangju, South Korea, with $20-30 \%$ disease incidence. Tospovirus-like spherical particles $(\sim 80-100 \mathrm{~nm}$ diameter) were observed by transmission electron microscopy from symptomatic leaves. Using a DAS-ELISA (Agdia, USA), single leaves from 12 symptomatic and two asymptomatic C. elegans plants were analyzed for impatiens necrotic spot virus (INSV) and tomato spotted wilt virus (TSWV), both previously reported as widespread in Korea. TSWV, but not INSV, was detected in all symptomatic leaves by DAS-ELISA, but not in asymptomatic leaves. To confirm TSWV infection, total RNA was extracted from five ELISA-positive samples and analyzed by RT-PCR using TSWV-specific primers (Choi et al. 2018). A 455-bp product of the expected amplicons was obtained from the five ELISA-positive samples. These amplicons were cloned and sequenced. All sequences were identical (NCBI accession number LC624145). A BLAST search revealed that TSWV-CE shared 95.3-99.5\% nucleotide identity with several TSWV isolates and greater than $99 \%$ identity with TSWV-EA (LC622166, Epipremnum aureum, Korea) and TSWV-Cir (LC570006, Cirsium setidens, Korea). Furthermore, 10 healthy $C$. elegans plants were mechanically inoculated with sap from TSWV-infected $C$. elegans plants. All plants showed mild mosaic and chlorotic ring spots

Rae-Dong Jeong

jraed2@jnu.ac.kr

1 Department of Applied Biology, Chonnam National

University, Gwangju 61185, Korea
14 days post-inoculation. TSWV infection was confirmed by RT-PCR and sequencing as above. To our knowledge, this is the first report of natural infection with TSWV in C. elegans in Korea; further surveys of TSWV infection in greenhouses will help prevent the spread of this viral disease in C. elegans.

Acknowledgements This work was supported by Korea Institute of Planning and Evaluation for Technology in Food, Agriculture, Forestry and Fisheries (IPET) through, Agriculture, Food and Rural Affairs Convergence Technologies Program for Educating Creative Global Leader Program, funded by Ministry of Agriculture, Food and Rural Affairs (MAFRA) (321001-03)

\section{Declarations}

Ethical approval This article does not contain any studies with human participants or animals performed by any of the authors.

Conflict of interest The authors declare that they have no conflict of interest.

\section{References}

Choi GW, Kim B, Ju H, Cho S, Seo E, Kim J, Park J, Hammond J, Lim HS (2018) Dual infections of tomato mosaic virus and tomato yellow leaf curl virus, or tomato mosaic virus and tomato chlorosis virus, detected in tomato fields located in Chungcheonnam-do in 2017. Korean J Agric Sci 45(1):38-42

Henderson A, Galeano G, Bernal R (1997) Field guide to the palms of the Americas. Princeton University Press, Princeton, NJ, USA

Publisher's Note Springer Nature remains neutral with regard to jurisdictional claims in published maps and institutional affiliations. 